\title{
A study on the need of assessment of settlement properties of coal mine waste dumps
}

\author{
RM Bishwal, Phalguni Sen and M Jawed \\ Department of Mining Engineering \\ Indian Institute of Technology (ISM) \\ Dhanbad, India \\ ram4091manohar@gmail.com
}

\begin{abstract}
Mining of coal deposits in excess of half a billion tons has resulted in a massive volume of coarse overburden (OB) material that is posing challenges in sustainable practice of waste handling and management. Ever increasing land demand for industrial or domestic purposes, mostly in urban or densely populated areas has necessitates better use of wastelands. However, a common problem in establishment of any kind of structure on a backfilled area is the unavailability of any generalized settlement properties of the materials, causing undervaluation of backfilled land. This paper describes the compaction characteristics of coal mine waste dump materials consist mostly of shale and sandstone; and its impact on settlement properties. The various factors influencing the settlement properties of a rockfill spoil dump is also described herein. A numerical analysis of settlement properties of spoil dump during and after construction stage is also presented with the help of PLAXIS software. This study will help in formulating better waste management guidelines in establishment of future waste dump structures in Indian coal mines.
\end{abstract}

Keywords-compaction; spoil dump; material gradation; soilrock material

\section{INTRODUCTION}

Coal mine spoil, a product of coal excavation consists of highly heterogeneous overburden (OB) of different materials, mostly of sedimentary origin [1]. These OB materials are often used in many geotechnical engineering works such as road or railway embankment, dam foundation, levee or dyke and sometimes as road subgrade, apart from backfilling operation in both opencast and underground mines. With ever increasing constraints of well-maintained land, lager areas of backfilled lands in most of the mines are gaining attention as a cheap source of land resources. The problem in utilization of such a huge amount of waste in the highly urbanized and industrialized region requires better method of handling these $\mathrm{OB}$ rock piles to maintain long term stability and sustainable environmental practice. In order to maintain stability of these structures, the $\mathrm{OB}$ materials therefore need a detailed characterization of their physico-mechanical properties. Among the various factors that affect stability are durability, crushing strength, mineralogical composition, shear strength parameters, where the stress-strain or settlement properties plays an important role. Naturally, a spoil dump undergoes settlement initially due to self-weight followed by weathering and crushing of materials. Although waste dumps are required to be stable for long term, the maintenance and its monitoring is not always a feasible task because of inaccessible location. Recurrent or short term stabilization of mine waste dumps are generally uneconomic [2] and therefore better focus is made right from the construction stage to avoid unwanted collapse in the future. The layer OB material formed during dumping should have minimum strength to support the overlying load without major deformation or settlement. Although a common practice of densification of waste material by compaction is followed in most of the coal mines, its effectiveness has not been accessed in details till now. Several research studies were conducted to study the compaction behaviour of mixtures of soft shale and hard rock such as limestone. However, one common problem in direct establishment of any infrastructure above it is due to the doubt over the reliability of these back filled materials. Due to the complexity involved in accessing the physicomechanical properties of the $\mathrm{OB}$ materials, till now no generalised criteria were available to predict the stability or settlement pattern of the structure constructed above it. In order to make any infrastructure sustainable over the backfilled structures a detailed analysis on the foundation condition and the settlement properties must be estimated. This paper presents a study on the necessity of proper compaction of mixed soil-rock materials, to reduce the settlement and improve materials properties.

\section{COMPACTION IN SPOIL DUMPS}

Compaction is a process of spatial rearrangement of solids to minimize the inter-granular void space by mechanical means. It helps in stabilization of the material by increasing the bulk density and hence minimizes the vertical settlement of the structure made on or above it. Compaction of such OB spoil material is influenced by numerous factor like material type, compactive effort and particle shape [3, 4, and 5], deformation, permeability [6, 7], angle of repose, etc., and hence it becomes difficult to generalize. Due to excessive presence of oversized and boulder type materials, the achieved compaction becomes very low and hence a higher rate of settlement is followed due to moisture addition [8] and grain crushing during 
loading [9, 10 and 11]. Although, it is not always require compacting all the waste dumps due to its lesser future prospective, it may be preferred if any future development over the filled materials is to be done. Although a minor form of compaction due to re-arrangement of materials is achieved by the movement of dumping vehicles and gravity $[12,13]$, it is not always sufficient to withstand infrastructure over it.

\section{Settlement Properties}

Coal mine spoils settle over time, initially due to selfweight followed by weathering and crushing of materials. The imposition of loads from overburden itself or the infrastructure made above can generate vertical deformation. These movements in the backfill structure may be termed as heave, creep settlement, collapse settlement and differential settlement depending upon the mechanisms of settlement [14]. Among all these pitfalls, differential settlement is known to cause maximum damage to any structures constructed upon the backfilled materials. The settlement mechanism may be caused either by a stress-induced crushing or by hydrocompression [15]. Stress-induced crushing occurs in dry mass when the inter-particle stresses become large enough to crush the particles at points of contact while hydrocompression is observed in wet spoil dumps. Hydrocompression is a major cause of settlement which weaken the bonding between grains may cause mobilization of fines content downward and it is most likely to observe if the materials are mostly silty, shaley and angular. Depending upon the distribution of fines and coarse content or its generation over time due to natural slaking, weathering and grain crushing may incites dump deformations at a large scale. As reported by Hills (1994), in design of any infrastructure over a backfilled area, a detailed understanding of the dumping operation and type, settlement time, drainage pattern, etc. together with the acceptable level of settlement decides the stability of the structure (Fig. 1).

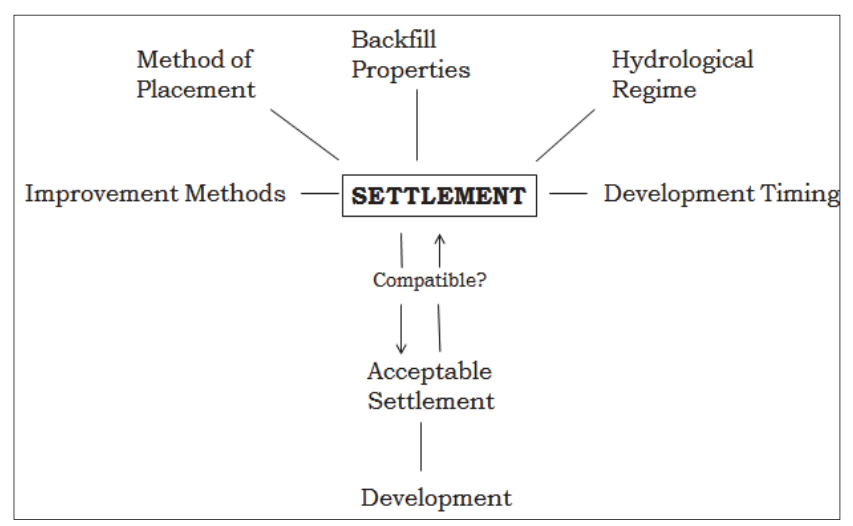

Fig. 1. Representation of the factors influencing opencast backfill settlement (After Hills, 1994)

\section{STUDY ON SETTLEMENT}

\section{A. Study Area}

The area chosen for the study was located closed to Indian School of Mines (ISM), Dhanbad. Kusunda-Alkusa colliery, an opencast project (OCP) of Bharat Coking Coal Limited (BCCL) under Jharia coalfield, Jharkhand with a leasehold area of $349.47 \mathrm{Ha}, 4-5 \mathrm{Km}$ was situated at a latitude: $23^{\circ} 44^{\prime} 12.73^{\prime \prime} \mathrm{N}$ to $23^{\circ} 46^{\prime} 28.02^{\prime \prime} \mathrm{N}$ and longitude: $86^{\circ} 22^{\prime} 54.6^{\prime \prime} \mathrm{E}$ to $86^{\circ} 25^{\prime} 38.5^{\prime \prime} \mathrm{E}$. The material formation in the overburden deposits consists of alternate layers of shale and sandstone and sometimes mixed formation, apart from a layer of soil and gravel at the top (Fig.-2). The average height/width of both working coal seam and OB bench stands at 10/15 m.
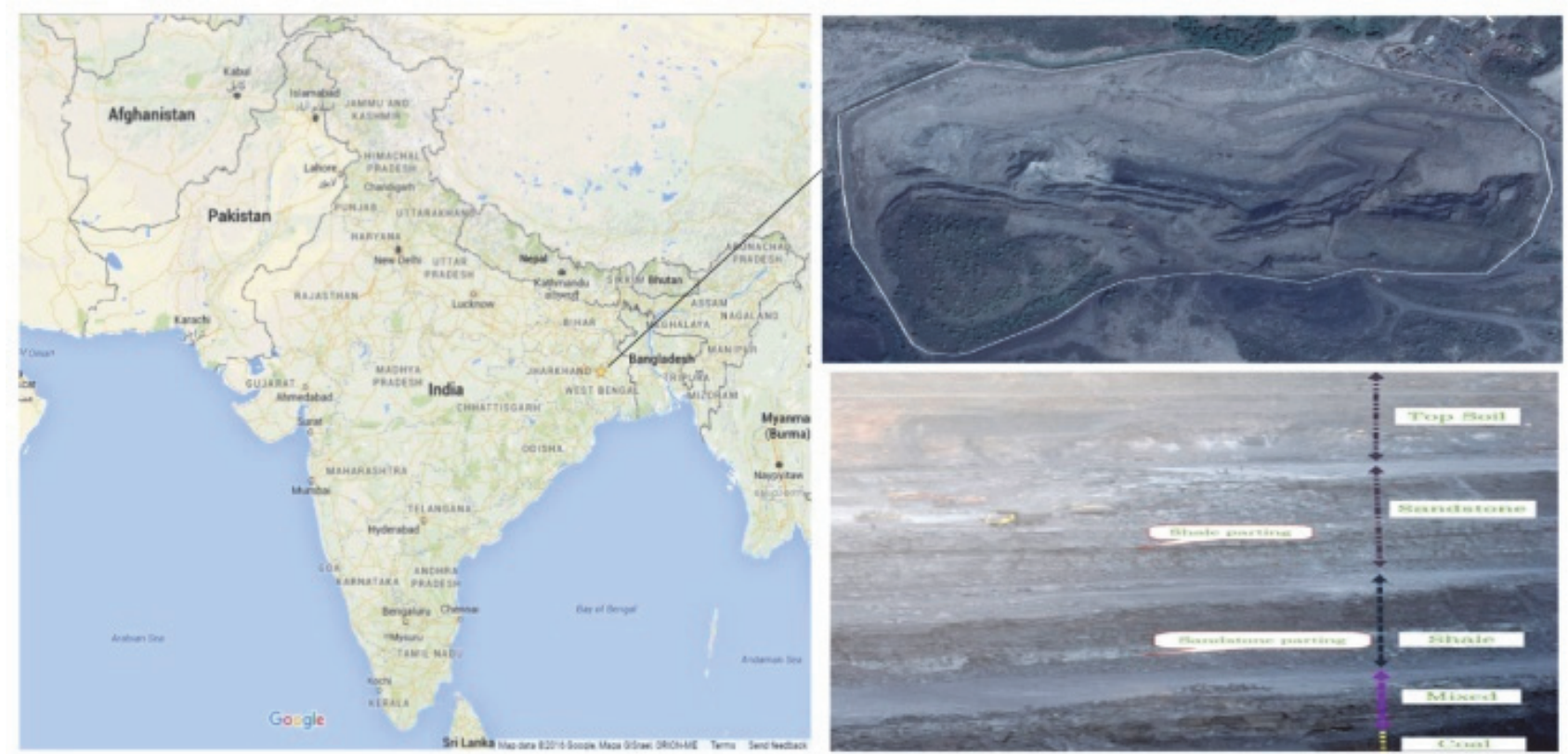

Fig. 2: Study area showing details of mines (Kusunda-Alkusa colliery, BCCL) 


\section{B. Material and Methods}

The samples collected from the Kusunda-Alkusa mines were prepared for obtaining the key indices and physicomechanical properties following standard testing procedures. The OB material containing shale and sandstone were chosen by visual inspection with the help of field experts and laboratory tests such as Atterberg's limit, direct shear box, specific gravity, hardness test etc. were conducted to obtain their properties.

\section{Numerical Analysis of Settlement}

To understand the settlement properties of the OB spoil dump, a numerical study based on Finite Element Analysis (FEA) was conducted with the use of numerical modelling tool PLAXIS 2D available at Indian School of Mines, Dhanbad. A spoil dump of having a dimension of $15 \mathrm{~m}$ height and $45 \mathrm{~m}$ length was made, while a foundation material containing clay layer of $10 \mathrm{~m}$ height was chosen (Fig. 3).
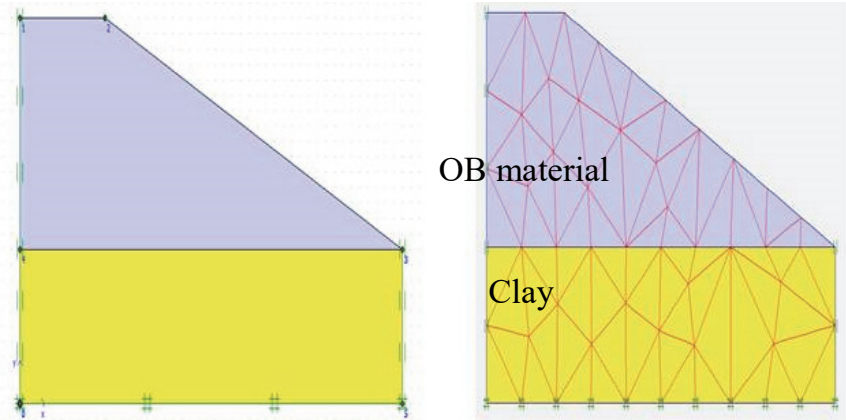

Fig.-3: Dump dimension and messing in PLAXIS 2D

\section{RESULT ANALYSIS}

The numerical analysis made throughPLAXIS was analysed and presented in the following section.In PLAXIS, the analysis was divided into four different stages, as construction stage for 60 days, consolidation stage for 30 days, consolidation till minimum pore water pressure i.e. $\mathrm{p}=1$ is achieved, and final stability stage considering Phi-C reduction. Detailed presentations of the stages are mentioned in Table-I as follows.

TABLE I. LIST OF PHASES IN NUMERICAL ANALYSIS IN PLAXIS

\begin{tabular}{|l|c|c|c|l|c|c|}
\hline \multicolumn{1}{|c|}{ Phase } & $\begin{array}{c}\text { Phase } \\
\text { No }\end{array}$ & $\begin{array}{l}\text { Start } \\
\text { Phase }\end{array}$ & $\begin{array}{c}\text { Calculation } \\
\text { type }\end{array}$ & Load input & $\begin{array}{c}\text { First } \\
\text { step }\end{array}$ & $\begin{array}{c}\text { Last } \\
\text { step }\end{array}$ \\
\hline Initial Phase & 0 & 0 & - & - & 0 & 0 \\
\hline Construction & 1 & 0 & Consolidation & $\begin{array}{l}\text { Staged } \\
\text { Construction }\end{array}$ & 1 & 2 \\
\hline Consolidation & 2 & 1 & Consolidation & $\begin{array}{l}\text { Staged } \\
\text { Construction }\end{array}$ & 3 & 3 \\
\hline $\begin{array}{l}\text { Full } \\
\text { consolidation }\end{array}$ & 3 & 2 & Consolidation & $\begin{array}{l}\text { Minimum } \\
\text { pore pressure }\end{array}$ & 4 & 13 \\
\hline Stability & 4 & 2 & $\begin{array}{l}\text { Phi/C } \\
\text { reduction }\end{array}$ & $\begin{array}{l}\text { Incremental } \\
\text { multipliers }\end{array}$ & 14 & 513 \\
\hline
\end{tabular}

As the study was conducted to know the settlement properties of the spoil embankment, only the vertical and horizontal settlement in terms of volumetric strain are presented herein (Fig. 4 through Fig. 7).

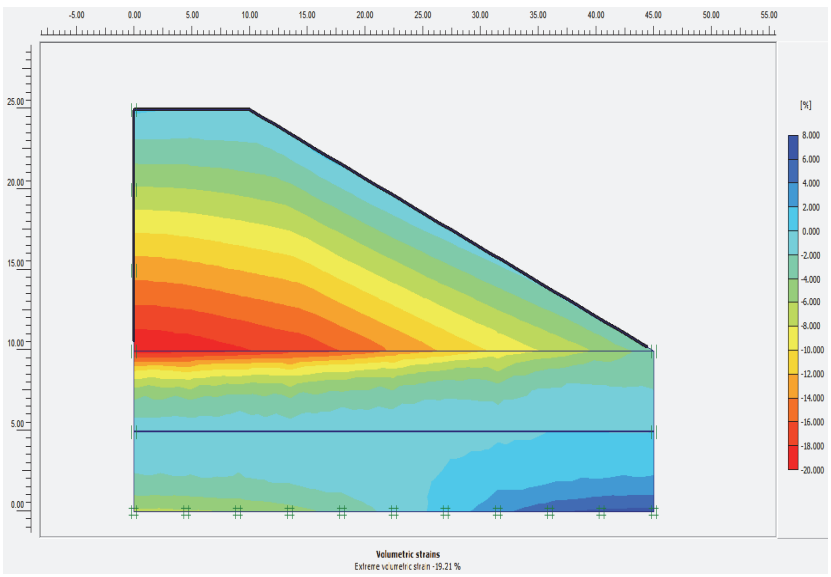

Fig. 4. Volumetric strain (\%) after 1st phase

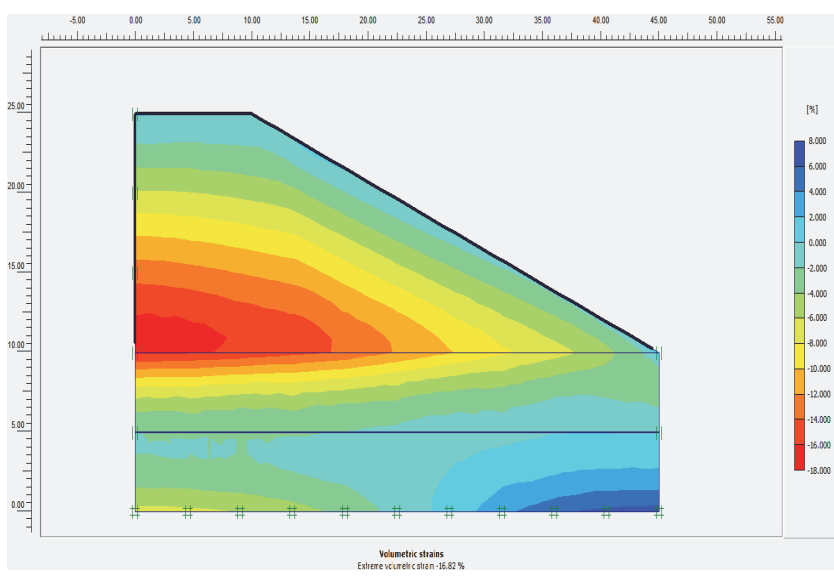

Fig. 5. Volumetric strain (\%) after 2nd phase

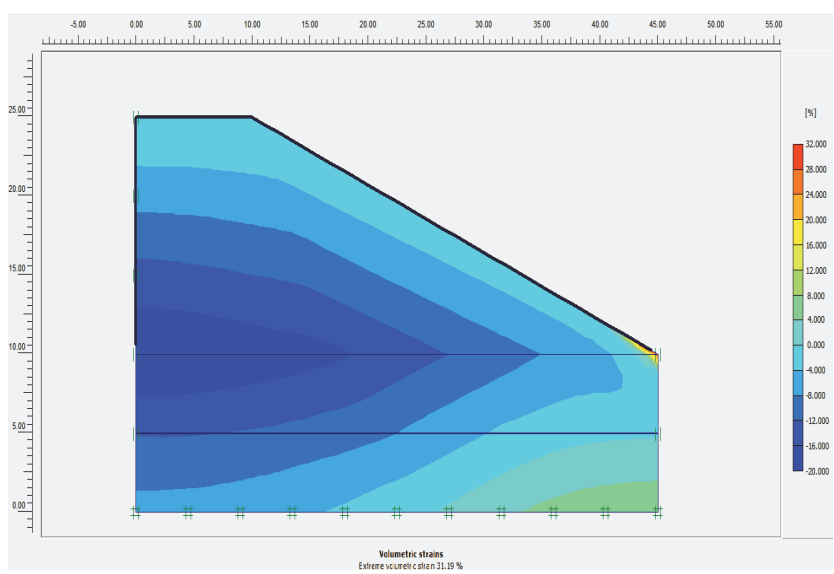

Fig. 6. Volumetric strain (\%) after 3rd phase

From the report, above mentioned figures, it can be observed that the volumetric strain in terms of percentage changes gradually varies from: $-19.21 \%,-16.82 \%,-31.19 \%$ and $-16.87 \%$ in successive stage of analysis. The spoil embankment is liable to settle due to self-loading, which can be evident from the results of the analysis showing volumetric reduction, assigned in terms of negative value. The highest value of settlement was observed during the full consolidation analysis ( $3^{\text {rd }}$ stage), which is in concurrent with the theoretical practice of soil mechanics. As the pore water 
pressure was reduced to its minimum, the structure achieves equilibrium, prior to achieving maximum settlement. However, a settlement due to $\mathrm{Phi} / \mathrm{C}$ reduction was also observed after the full consolidation stage. The final structure of the spoil dump after 30 days consolidation can be observed from the deformed mess of the geometry, as shown in Fig. 8 as follows.

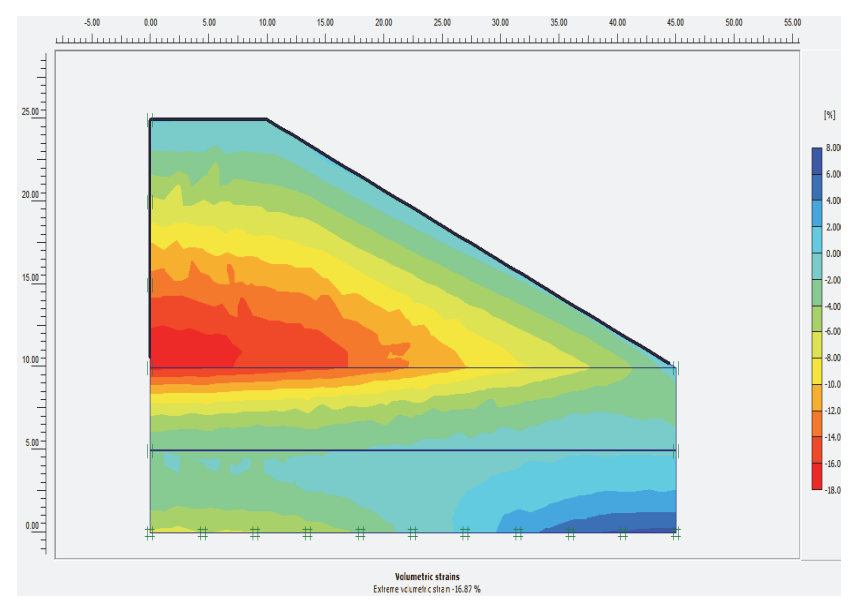

Fig. 7. Volumetric strain (\%) after Final phase

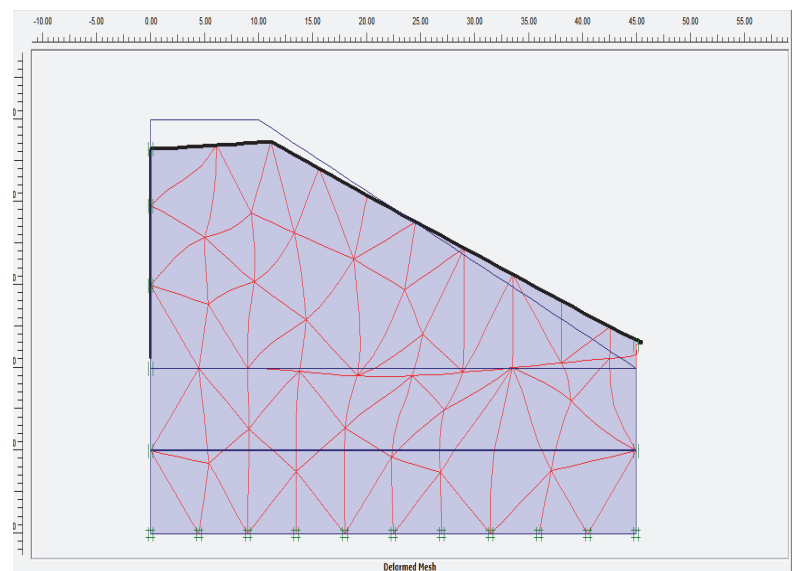

Fig. 8. Deformed mess after final stage

\section{CONCLUSIONS AND DISCUSSION}

The stability and maintenance of backfilled structures and spoil dumps plays an important role in establishment of any structure on or above it. With the recent rate of increase in coal production to reduce dependency on import, the amount overburden waste generated will be very high in the future. Storage and management of such structure requires a better way understanding the stability and settlement properties of the backfilled land. As the compaction and hence the settlement of spoil dump is generally affected by material gradation, dumping rate, dumping method, lift thickness, water table, bulk density, etc., it is very difficult to control settlement in spoil dumps. Although the stability of these structures can be improved though compaction these are found to be not effective in many cases due to unavailability of specialized equipment and cost factors. Numerical analysis of settlement using PLAXIS module can be useful in predicting settlement and stability of a backfilled structure through each stage of construction, a feature commonly not available in other numerical analysis tools such as FLAC, GALENA. It can be used to know the settlement pattern during each bench or lift of dump formation.

\section{REFERENCES}

[1] S. Fityus, G. Hancock and T. Wells, "Geotechnical characterization of coal mine spoil," Australian Geomechancis, 43(3), pp.13-22, 2008.

[2] G.E. Blight and F. Amponsah-Dacosta,"Erosional stability of tailings dam slopes, chapter in Ground Water Bioengineering for Erosion Control,” Barker, D.et al (eds), Science Publishers Inc, USA . 2004.

[3] I.H. Hamdani, "Optimum moisture content for compacting soils onepoint method," J. Irrig. Drain. Eng. 109 (2), pp. 232-237, 1983.

[4] L.R. Blotz,C.H. Benson andG.P. Boutwell, "Estimating optimum water content and maximum dry unit weight for compacted clays" J Geotech Geoenviron Eng. ASCE 124(9):907-912. doi:10.1061/(ASCE)1090-0241(1998)124:9(907), 1998.

[5] G.C. Cho, J. Dodds and J.C. Santamarina, "Particle shape effects on packing density, stiffness, and strength: natural and crushed sands," J Geotech Geoenvironmental Eng. ASCE 132(5):591-602. doi:10.1061/(ASCE)1090-0241(2006)132:5(591), 2006.

[6] Z.L. Yan, J.J. Wang and H.J. Chai,"Influence of water level fluctuation on phreatic line in silty soil model slope. Eng. Geol. 113(1-4), 90-98, 2010.

[7] J.J. Wang, H.P. Zhang, D.P. Deng and M.W. Liu,"Effects of mudstone particle content on compaction behaviour and particle crushing of a crushed sandstone-mudstone particle mixture," Eng. Geology 167:1-5. doi:10.1016/j.enggeo.2013.10.004, 2013.

[8] John N. Cernica, "Geotechnical Engineering. New York: Holt, Rinehart and Winston, 1982.

[9] M.R. Coop, K.K. Sorensen, T.B. Freitas, G. Georgoutsos, "Particle breakage during shearing of a carbonate sand" Geotechnique 54(3), 157-163 (20) Result analysis

[10] S. Lobo-Guerrero and L.E. Vallejo,"Discrete element method evaluation of granular crushing under direct shear test conditions. J Geotech Geoenvir Eng ASCE 131(10):1295-1300. doi:10.1061/(ASCE)1090-0241(2005)131:10(1295), 2005.

[11] F. Casini andG.M.B. Viggiani, "Experimental investigation of the evolution of grading of an artificial material with crushable grains under different loading conditions," In: Proceedings of the 5th International Symposium on Deformation Characteristics of Geomaterials, Seoul, Korea, pp. 957-964, 2011.

[12] A.W. Bishop, "The use of the slip circle in the stability analysis of slopes," Geotechnique, Vol. 5, pp. 7-17, 1955.

[13] Kölsch, Fricke, Mahler, "Damanhuri Stability of landfills - The Bandung disaster," CISA (eds.): Proceedings of the 10th International Landfill Symposium, Cagliari (Italy). 2005.

[14] C.W.W. Hills, "The Examination and Prediction of Opencast Backfill Settlement," PhD thesis, University of Nottingham, UK. 1994.

[15] W.A.Karem, M.E. Kalinski, and D.E. Hancher, "Settlement of mine spoil fill from water infiltration: a case study in Eastern Kentucky. Journal of Performance of Constructed Facilities, 21(5), 345-350, (2007). 